one-third and the balance will be met out of a donation from the Sir J. C. Bose Trust No. 1. Plans have been approved for the erection of a two-storied structure of floor area about $3,500 \mathrm{sq}$. $\mathrm{ft}$. at the south-west corner of the Institute quadrangle, at an estimated cost of Rs. 80,000, of which half has been given by the Sir J. C. Bose Trust No. 1, and the Central Government has been asked to contribute an equal amount. This building will house the workshop and the library, which have outgrown their present accommodation. At the Mayapuri Research Station, Darjeeling, a glass-house and a microbiological laboratory have been fitted up for the study of potato virus disease and for the survey of the distribution, at different altitudes, of soil micro-organisms in cultivated and virgin soils of the Darjeeling district.

Two research fellows recently returned from the United States and Canada are constructing apparatus for cosmic ray investigations, which will be taken to Darjeeling next spring for experiments at high altitudes. These include a large pressure ionizaticn chamber, counter telescopes, a large rectangular Wilson chamber, and a small Wilson chamber placed in the field of a medium-sized electromagnet consuming $25 \mathrm{~kW}$.

The cytological and mutagenic action of X-rays, ultra-violet rays, ultrasonic radiation, as well as of different chemical reagents, is being investigated. As reported previously, improved mutants of jute have been obtained with X-ray treatment ; recently plants grown from irradiated Sesamum seeds appear to give a promising yield of oil-seeds. The effect of penicillin in inhibiting the growth of soil organisms and producing cytological effects on plant colls has been studied. Pericillin has been found to prevent the transformation of tadpoles into frogs; tadpoles kept for some time in a dilute penicillin solution and then transformed to their normal habitat in water have continued to grow and increase in size for six months without metamorphosing into frogs.

\section{OVERSEAS FOOD CORPORATION}

7 HE report of the Overseas Food Corporation*, to which are appended the accounts for the year ended March 31, 1951, some notes on land-use surveys and the report of the Scientific Department for the crop year 1949-50, records steady progress towards the decentralization foreshadowed in the previous report and rapid implementation of the recommendations of the Kongwa Working Party's report of September 1950 .

Before the 1950-51 planting season, agricultural operations were reduced to the four comparatively small farms recommended. Management of smaller acreages by the more experienced farmers and a better distribution of rainfall in the critical months of January and February demonstrated the potential of the area more favourably. Land clearing in Urambo was virtually completed at 65,000 acres, and full-scale farming established with 45,000 acres planted. Clearing in the Southern Province was limited to the 60,000 acres recommended as a first stage in the revised plan presented to Parliament in January 1951, and all money advanced to the Corporation for the East African Groundnut Scheme up to March 31, 1951, has been written off. Hand labour is being substituted for the mechanical processes of piling the felled trees and excavating stumps.

* Overseas Food Corporation. Annual Report and Statement of Accounts for the Year ended 31st March 1951. Pp. iv +82. (London :
H.M. Stationery Office, 1951.) 3s. net.
The notes on land-use surveys indicate the contribution made by the Corporation to the technique involved ; waste of much labour in clearing unsuitable land both in Urambo and the Southern Province has been saved by land-use surveys and soil conservation surveys. Observations in all areas confirmed the view that consistent and informed consideration must be given to the intricate problems of the loss of soil and soluble plant foods through surface wash and the leaching of the principal plant foods during periods of early and high-intensity rainfall. Demarcation technique has been improved by a method developed locally in the use of aerial photographs, and encouraging results were obtained in a series of controlled experiments in the artificial precipitation of rain at Kongwa, using the silver iodide technique.

Virginia tobacco trials at Urambo were encouraging, both as regard the growth and health of the plants and the quality of the leaf from the barns. Cotton trials in all three regions showed fair to good growth, but 'stainer' attack threatens to be an economic problem. Encouraging results were obtained in trials of several varieties of rice on thirty acres at Urambo. At Kongwa the 1949-50 harvest yield per acre was $244 \mathrm{lb}$. shelled groundnuts, $99 \mathrm{lb}$. cleaned sunflower and 1,085 lb. shelled maize.

The Scientific Department continued to work on lines laid down in previous seasons, but little detailed work on sunflower was conducted in 1949-50 and 1950-51, since until a self-pollinating type can be developed which is also dwarf, drought-resistant and uniform for combining, other agronomic work on this crop is of little significance. At Urambo a system of so-called 'broad lands' has been developed which holds much promise for control of surface 'wash', an insidious and very serious cause of reduced yields, and this system is to be applied more generally in experimental work. The classification of soil types at Kongwa and in the Southern Province was completed for practical purposes.

Soil fertility studies in 1949-50 showed widespread and important phosphate deficiencies in most soils of the Southern Province and confirmed the general phosphate deficiency of the Kongwa soils. The principal plant-food deficiency at Urambo is nitrogen. This deficiency was more prominent in 1950-51 and may be expected to increase unless remedied by agricultural practice, such as adoption of measures to check the mineralization and leaching of nitrogen.

Work on soil-borne diseases has shown the presence at Urambo and in the Southern Province of Sclerotium rolfsii, a very serious disease of groundnuts and other crops in South Africa, although the incidence is at present small. The main plant disease with which the Department is concerned continues to be the rosette disease of groundnuts, and detailed field studies have continued on the biology of the aphis vector and its relation with predators, and on the carry-over of the disease in dry-season volunteer groundnuts. The use of systemic insecticides for controlling secondary multiplication of aphides is also being studied. A valuable degree of control of termite attack on standing crops has been obtained experimentally by the use of 'Gammexane', placed near the seed, as a soil fumigant.

The Operational Research Unit continued to work along the broad lines described in the annual report for 1949-50, and a new digger-lifter-windrower and a new spray winch were developed. The East African Scientific Committeo met twice during the year. 